INGENIUM ET POTENTIA

Revista Electrónica Multidisciplinaria de Ciencias Básicas, Ingeniería y Arquitectura

Año II. Vol II. N³. Julio - Diciembre, 2020

Hecho el depósito de Ley: FA2019000052

FUNDACIÓN KOINONIA (F.K).

Santa Ana de Coro, Venezuela.

Ing. Damil José Maldonado-Mosquera. MSc.

http://dx.doi.org/10.35381/i.p.v3i5.1373

\title{
Aporte de la Ingeniería en la pandemia
}

La COVID-19 es una infección ocasionada por una nueva especie de coronavirus, conocido como SARS-CoV-2 (Síndrome respiratorio agudo severo coronavirus 2). Esta enfermedad ha generado la pandemia más grande experimentada a nivel mundial en las últimas décadas. Al respecto, el sector salud ha sido el ente rector de estudiar, contener y mitigar la propagación de esta enfermedad. Sin embargo, existen otras disciplinas que han diseñado estrategias con el fin de ayudar a la crisis global. Una de estas disciplinas es la ingeniería y sus innovaciones y aportes logísticos.

El papel de la ingeniería en la pandemia COVID-19, ha sido de grandes aportes y contribuciones, dentro de los cuales es conveniente mencionar el diseño de equipos y elementos de protección personal (EPP). Teniendo en cuenta la forma de transmisión de la enfermedad a través de gotitas respiratorias y el alto riesgo de contagio del personal médico que se encuentra trabajando por la mitigación y contención de la infección. En la actualidad en el área de ingeniería se están desarrollando investigaciones y esfuerzos en la creación de mascarillas que inactiven las partículas virales que puedan ser expulsadas, así como en el desarrollo de trajes inteligentes y multifuncionales equipados con capacidades de comunicación inalámbrica y microsensores para detectar el virus, controlar la humedad y la temperatura y monitorear las condiciones fisiológicas de los médicos sin comprometer la función protectora y la flexibilidad.

En este mismo orden de ideas, están los equipos de tratamiento y prevención como la construcción de los ventiladores artificiales. Sin embargo, hay otros aspectos de tratamiento y prevención en los que trabajan los equipos de ingenieros, como un aerosol nasal guiado como candidato a la forma de aplicación de una vacuna intranasal. Por otro lado, la ingeniería se ocupa de la optimización de procesos en general, y esto incluye otros aspectos del manejo de la pandemia, como la creación del "COVID-19 queueing game", una estrategia que permite disminuir el riesgo de infección en asistencia a 
NGENIUM ET POTENTIA

Revista Electrónica Multidisciplinaria de Ciencias Básicas, Ingeniería y Arquitectura

Año II. Vol II. N³. Julio - Diciembre, 2020

Hecho el depósito de Ley: FA2019000052

FUNDACIÓN KOINONIA (F.K)

Santa Ana de Coro, Venezuela.

Ing. Damil José Maldonado-Mosquera. MSc.

supermercados o establecimientos públicos controlando el número máximo de compradores por tienda y el de clientes en el área de caja.

Ing. Damil José Maldonado-Mosquera. MSc.

damilmaldonado@gmail.com

Red de Investigación Koinonía, Santa Ana de Coro

Venezuela

https://orcid.org/0000-0002-5662-9540 